\title{
Design and Realization of Manchu Intangible Cultural Heritage Digital Exhibition Center Based on VR Technology
}

\author{
Junbo Dai \\ The Library \\ Tonghua Normal University \\ Tonghua, China 134002
}

\author{
Lishu Zhang \\ The Library \\ Aviation University of Airforce \\ Changchun, China
}

\begin{abstract}
Virtual reality technology provides a new technology for the protection of Manchu intangible cultural heritage. Through material collection, scenario modeling, interactive design, data connectivity, package release to build the three-dimensional digital exhibition center with real user experience and effect close to the original image, so to make fully and real performance for the Manchu intangible cultural heritage with rich content and various forms. The digital exhibition center can access the Internet, break the limitation of time and space, so that more and more people can feel the unique charm of Manchu intangible cultural heritage.
\end{abstract}

\section{Keywords—virtual reality; Manchu; digital exhibition center}

\section{INTRODUCTION}

Manchu is an important part of China's 56 ethnic groups, and it left rich intangible cultural heritage in the long history of Chinese civilization. As China's constant attention of intangible cultural heritage protection, various types of heritage projects with full of Manchu folk culture characteristics is gradually increasing and improvement and the Manchu intangible cultural heritage is gradually radiate its unique charm of vitality. With the rapid development of science and technology, virtual reality technology brought new technology for the intangible cultural heritage protection work, its superior performance and real-life experience make the recover and reappear of all kinds of heritage possible. This article describes the process to build interactive, easy to operate and multiple exhibit method three-dimensional virtual reality exhibition center which based on Manchu folk art museum.

\section{OVERVIEW OF MANCHU INTANGIBLE CULTURAL HERITAGE PROTECTION WORK}

Man has a long history. Its origin can be traced back to Sushen ethnic from Chinese historical records described in BC. On the vast Northeast Plain, the Manchu people survived in their own hard work and ingenuity, through long historical changes, gradually formed its own national language, national character, religious beliefs, customs and practices etc., in the oral tradition and expressions, performing arts, social practices, rituals and festive events, knowledge about nature and the universe and practices, traditional craftsmanship all aspects have preserved Manchu intangible cultural heritage. Until October 2014, the Manchu culture related provincial intangible cultural heritage projects are 116, including the 9 national intangible cultural heritage projects, 107 provincial intangible cultural heritage projects, and the Changbai Mountain Manchu Chinese paper-cut was took by UNESCO into the List of intangible cultural heritage of mankind as the identity of Chinese paper-cut. We can see the importance of Manchu culture in human civilization and splendid culture of the Chinese nation. At the same time, Manchu Nationality and Folk Museums have been established gradually around the country, so far there are dozens of Manchu Folk Museums including Beijing Manchu Folk Museum, Anshan Xiuyan Manchu Museum, Yitong Manchu Autonomous County Museum, Jilin Manchu Museum, Changbai Mountain Manchu culture museum which allow the systemic preservation and inheritance of Manchu intangible cultural heritage. December 2003 in Jilin Tonghua Normal University established Manchu folk art gallery which is the first Manchu folk art gallery in China. The nearly thousand pieces of precious collections including embroidery, knitting basket, paper cutting, furniture and others have very important artistic and academic value. After more than ten years of development and construction, it has became a larger Manchu folk art museum, the number of collections, academic and artistic value have increased dramatically, the vast majority of the display items are provided by the famous Manchu culture expert, Professor of Tonghua Normal University Wangchun Xin and his daughter Wang Ji, as well as teachers and students from Tonghua Normal University who focus on the research work of Manchu intangible cultural heritage. They have gone through over 30 years, carrying a variety of camera equipments, collecting those fine arts used to be normal everywhere but today disappeared in the thousands villages of Northeast China. They have accumulated a lot of Fieldwork data. The hard work not only provides a rich variety of display items for the Manchu folk art museum , the in-depth and meticulous research data also makes these items approached in modern people's vision with the face which nearest to reality and restore its former vitality. Also it has played a very important role for Manchu intangible cultural heritage protection. 


\section{OVERVIEW OF VIRTUAL REALITY TECHNOLOGY}

Virtual Reality is translated from the English words Virtual Reality, referred as VR technology. It is a technology to use computer technology to generate the objective existence of something or does not exist as virtual environment in front of the users, and make users immersed in a virtual environment [1]. Virtual reality technology combines computer technology and the human thinking science together to make human beings can interact with virtual environment through eyes, ears, hands, brain and other body organs, although they are not personally on the scene, but they can feel the real field of vision, sound, speed, even texture and force. Thereby effectively extending human cognitive means improves the sensual and rational knowledge to objective things. The software of 3D Studio Max, Virtual Reality Platform and others also makes this technology no longer mysterious and expensive. 3D Studio Max can use basic geometry modeling, two-dimensional graphics modeling, extrusion modeling, turning modeling, lofting modeling, polygon modeling combined with Virtual Reality Modeling Language (VRML) to established basic models and scenarios. 而 Virtual Reality Platform 能和 3D Studio Max Virtual Reality Platform and 3D Studio Max can be seamless connected, it can simulate high efficiency and precision physical impact, and support navigation display and angle switching. The user can use the mouse, keyboard, events trigger timing trigger to interact in various ways with the three-dimensional objects in the scene. For this reason, virtual reality technology and applications continue to be developed in all areas of human life. Such as "Live Web cast" of Shanghai World Expo 2010 is through virtual reality technology to create a Expo area which can provide experience simulation and interactive games, so the audience who can not go to the Expo can truly understand the various venues in the park; production of motor vehicle driver's exam through virtual reality technology to simulate real driving routes, obstacles, traffic signs and others based exam requirements for the candidates so that candidates can experience forward, cornering, braking and other operational effect in absolute security environment, it can significantly reduce operational risk for beginner of motor vehicle driving. Applications such as these are in medicine, education, and tourism and real estate areas. Virtual reality technology with its unique advantages, strong creativity and broad applicability lead us into a colorful new world.

\section{The Significance to Use Virtual Reality TEChNOLOGY FOR PROTECTING MANCHU INTANGIBLE CUltural Heritage}

First, the virtual reality technology built three-dimensional space can restore the true face of Manchu intangible cultural heritage better than any other technology. The most important thing for heritage protection is to maintain the true face of heritage in their distant age, virtual reality technology is just able to build the digital model based on physical or pictures of the heritage and combined with the existing raw data. And through building a scene with consistent ratio, same color texture, realistic light, vivid gesture and consistent with its characteristics of the times, creating a real existing environment which shows its unique charm. Second, virtual reality technology provides a more diverse presentation for Manchu intangible cultural heritage, it can through different perspectives, different tracks, different distances, with sound and text content to conduct fully and multi-technique expression for the heritage, so that people can feel more cultural connotation carried by cultural heritage ;Third, Manchu intangible cultural heritage has diversity species and rich forms, for some word of mouth alone art exhibit ,itself is unable to show its content features, but virtual reality technology can combine three-dimensional animation and video to make vivid and detailed performance of heritage connotation; in addition, virtual reality technology makes the distance between people and Manchu intangible cultural heritage closer, through virtual reality technology to create a digital exhibition and publish in the form of website without space and time limit, as long as the network unobstructed and hardware configurations reach the standard, visitors can visit exhibition at anyplace and anytime, it is like to go back to the ancient times to explore and understand information of each collection in filed. This also provides a convenient for more people to understand and recognize the Manchu intangible cultural heritage, it opened up a new path for the faster and further development of Manchu intangible cultural heritage. In short, the many advantages of virtual reality technology will make it a powerful tool for Manchu intangible cultural heritage protection.

\section{THE DESIGN AND IMPLEMENTATION OF MANCHU} INTANGIBLE CULTURAL HERITAGE DIGITAL EXHIBITION WITH VIRTUAL REALITY TECHNOLOGY

The design and implementation of Manchu intangible cultural heritage digital exhibition is a systematic process that requires carefully collect, collate, screening, sorting, processing, production, modeling a series work for rich content and various forms of heritage items, and gradually built a fully functional, easy operate, real effect digital exhibition. Implementation process shown in "Fig. 1". 


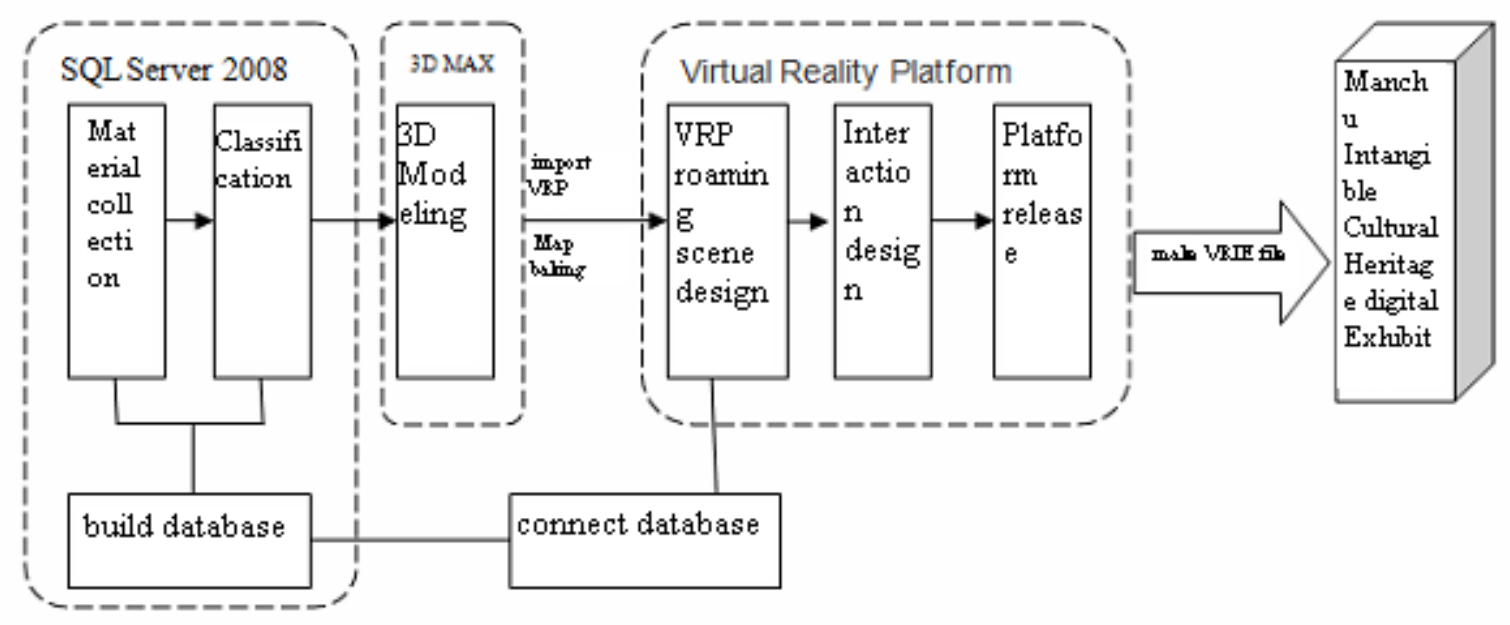

Fig. 1. Manchu Intangible Cultural Heritage digital Exhibition Design and implementation flow chart

\section{A. Material Collection}

Manchu Intangible Cultural Heritage digital Exhibition take Tonghua Normal University Manchu folk art museum as a prototype for simulation construction, material collection is from the physical pavilion main types of collections, these precious materials are from the years of fieldwork, private visits, carefully collected by Tonghua Normal University Manchu folk art research center's staff, including embroidery, knitting baskets, clothing, paper cutting, furniture, food, construction, etc. The items mainly are physical and imagebased content, as well as text material, sound, and videos. The vast majority of these raw materials belong to unprocessed zero document, in order to be able to display digital exhibits with clear category and complete information, we must first screen all kinds of materials, some redundancy, incomplete or even wrong material must be screened out; then we need to modified and perfected on the materials, such as audio and video files editing, image color correction, text materials sorting and finally, through the classification of filtered material which according to China's Intangible cultural heritage list, these materials will be divided into various types of material: folk literature, folk music, folk dance, traditional theater, folk arts, athletics and acrobatics, folk fine arts, traditional handicrafts, traditional medicine, folk, ten class. Subdivide embroidery, knitting baskets, clothing, paper cutting, Yangko, food, construction and others into the secondary category according to the specific content. In this way, such a wide variety of materials can be systematically entered into the database. The system uses SQL Server 2008 to manage the database, basic information and standard input as shown in "Table I".
TABLE I. MANCHU IntangiBle CUltural HeRITAgE EXHIBITION DIGITAL DATA BASIC INFORMATION TABLE

\begin{tabular}{|c|c|c|}
\hline Category & Content & Standard \\
\hline $\begin{array}{l}\text { Serial } \\
\text { number }\end{array}$ & identify each item & $\begin{array}{l}\text { with uniqueness, can trace item by } \\
\text { its unique number }\end{array}$ \\
\hline Name & Item name & $\begin{array}{l}\text { include byname, folk name and so } \\
\text { on }\end{array}$ \\
\hline Theme & item related theme & text format \\
\hline Key word & $\begin{array}{l}\text { key word to } \\
\text { describe the item }\end{array}$ & text format \\
\hline $\begin{array}{l}\text { First } \\
\text { category }\end{array}$ & $\begin{array}{l}\text { first category the } \\
\text { item belong to }\end{array}$ & $\begin{array}{l}\text { Include folk literature, folk music, } \\
\text { folk dance, traditional theater, folk } \\
\text { arts, athletics and acrobatics, folk } \\
\text { fine arts, traditional handicrafts, } \\
\text { traditional medicine, folk }\end{array}$ \\
\hline $\begin{array}{l}\text { Second } \\
\text { category }\end{array}$ & $\begin{array}{l}\text { second category } \\
\text { the item belong to }\end{array}$ & $\begin{array}{l}\text { Divided from the first category } \\
\text { include:embroidery, knitting } \\
\text { baskets, clothing, paper cutting, } \\
\text { Yangko, food, construction }\end{array}$ \\
\hline $\begin{array}{l}\text { Acquisition } \\
\text { time }\end{array}$ & $\begin{array}{l}\text { the time for the } \\
\text { item to enter the } \\
\text { museum }\end{array}$ & Date format: $1990-01-01$ \\
\hline Source & $\begin{array}{l}\text { the source and } \\
\text { birthland of the } \\
\text { item }\end{array}$ & text format \\
\hline $\begin{array}{l}\text { Brief } \\
\text { introduction }\end{array}$ & $\begin{array}{l}\text { brief introduction } \\
\text { for the item }\end{array}$ & text format \\
\hline Format & $\begin{array}{l}\text { digital format of } \\
\text { the entering } \\
\text { document, such } \\
\text { like bmp,jpg. }\end{array}$ & text format \\
\hline $\begin{array}{l}\text { Link } \\
\text { address }\end{array}$ & $\begin{array}{l}\text { the internet address } \\
\text { of this document }\end{array}$ & $\begin{array}{l}\text { Through this address can download } \\
\text { document resource like text, } \\
\text { image, audio and video. }\end{array}$ \\
\hline
\end{tabular}

\section{B. Modeling and Baking}

Through modeling and baking, create a three-dimensional Manchu intangible cultural heritage digital exhibition space scenes and three-dimensional model for each item. The first step, use 3D design software 3D Studio Max for basic modeling foundation, the initial time of modeling is primarily based on physical items and the original two-dimensional images to make three-dimensional simulation construction of the museum and physical item body. At first build 10 
exhibition halls include: folk literature exhibition, folk music hall, folk dance hall, a traditional theater hall, folk art exhibition, acrobatics and athletics hall, folk art exhibition, traditional handicrafts exhibition, traditional medicine hall, folk hall, based on database classification, then build models based on filtered materials requires to have the same ratio with the original item, same color and texture of the original item. If there are material description text, then the model should be constructed based on the text, if there is an existing physical object, then the model can be replaced by loop shooting video of the object. Meanwhile, in order to limit the size of the model file within the scope of the system running smoothly, we must use some modeling techniques, such as: remove redundant plane, try to use the inerratic geometry and so on; the second step, use Virtual Reality Platform (referred VRP) import the basic 3D model for further processing. Since heritage species are rich and varied, if totally dependent on the initial modeling to create the perfect collection is bound to give a heavy burden on the computer system and affect response speed, and "baking" technology can solve this problem. The method is to use Photoshop image processing software to make crop, twist, tilt, contrast, brightness, color balance process to the picture material and get image element which suitable for VRP use, and then baking in the VRP with Lighting map function, "paste" the elements on the position which can be aware by sight line so that makes threedimensional modeling get a "lightweight" texture coat, and then give a reasonable light, can achieved more realistic effect for collections and so to achieve the purpose to restore the heritage information. Meanwhile, in addition to import basic $3 \mathrm{D}$ model, we need to design appropriate multimedia window on the needed location, so some video, audio and other media type collections can be played, browsed by the window; the third step, the corresponding scene landscaping, making collection coordinate with the environment, giving the collection a more intense flavor of the times. Since the foundation of the model has been generated, it can use the "reference examples" method to point some duplicate items with a pointer, which can greatly reduce the burden on system operation. Modeling and baking is the most critical phase of the virtual scene construction, also it is the phase with largest amount of work, most difficult, most detailed and most tedious, modeling for each collection and each scene are directly determines the practical experience of viewers for the digital Exhibition.

\section{Interactive Design}

The ultimate goal of virtual reality is to achieve people can make watching, walking, reading and other activities in a virtual scene by operating a computer, they can feel all kinds of information for the objective things. So that only complete scene design is not enough, we need VRP to design movement response consistent with the reality experience. Establish walking camera can achieve flexible "first person" roaming walking experience effect from different perspectives, different distances, through setting walking camera perspective, walking pattern, speed and other parameters can make walking experience more real; at the same time start the physical collision detection in the scene can avoid browsing through the wall and stepped foot into the footstep phenomenon. In order not to affect response speed, collision detection surface setting should be as little as possible, some surface that will not collide such as a ceiling, items behind the fence do not need to set collision detection. In addition to the interaction in the scene, the digital exhibition also provides interactive functions, since we set up the operation button and multimedia windows, so the views can click button to know more information about the items such like the relevant videos, audios, text and so on.

\section{Database Connection and Release}

Use database plug-in from VRP editor, enter the server name, database name and account information via ADO data interface to connect VRP and SQL Server database, establish a "linked operations" with exhibit model and the database and thus be able to read basic information of each collection in the VRP environment, such as serial number, name, brief description and so on; and then edited in the VRP script editor to achieve click the effect of click "collection Details" button to see the text information. This allows a more detailed understanding of additional information about the collections while enjoying the original collections at the same time, giving the collection a more complete expression. VRP file after editing can be packaged and released as VRPIE file which can be embedded directly in the page, link it to the existing "Manchu intangible cultural heritage website" can access to the Manchu intangible cultural heritage digital exhibition at anytime and anyplace.

\section{CONCLUSION}

Using virtual reality technology to build digital Manchu intangible cultural heritage exhibition so that people can stay at home to visit the many Manchu intangible cultural heritage, understand its rich culture, feel the breath of its long history and its unique charm ethnic characteristics. This makes the protection of Manchu intangible cultural heritage upgraded to a new level, and also opened up a new road for the Manchu intangible cultural heritage to the world.

\section{REFERENCES}

[1] Zhang Jing virtual reality technology and its application [M] Beijing: Tsinghua University Press, 2011.

[2] Liu Guangran virtual reality technology [M] Beijing: Tsinghua University Press, 2011.

[3] Liu Cheng online exhibition design and implementation based on VRPIE [J] Information and Communication, 2011 (08): 119-121.

[4] Zhang Jing Architecture rehabilitationof Shanxi University based on virtual reality technology [J] Computer Simulation, 2012 (11): 20-25.

[5] http://baike.baidu.com/view/2314.htm?fr=aladdin\#reference-[10]-2314wrap Baidu Encyclopedia Intangible Cultural Heritage.

[6] http://govinfo.nlc.gov.cn/ Chinese government public information service platform integration. 